\title{
Correction: Field determination of the hydraulic conductivity of a compacted sand layer controlling water flow on an experimental mine waste rock pile
}

\author{
Marie-Lin Bréard Lanoix ${ }^{1,2,3}$. Thomas Pabst ${ }^{1,2}$. Michel Aubertin ${ }^{1,2}$
}

Published online: 18 March 2020

(C) Springer-Verlag GmbH Germany, part of Springer Nature 2020

\section{Correction: Hydrogeology Journal}

https://doi.org/10.1007/s10040-020-02129-7

Equations 4 and 5 were incorrectly displayed in the original article. The corrected equations are:

$\mathrm{KC}: k_{\mathrm{sat}}=\frac{C \cdot g}{\mu_{\mathrm{w}} \rho_{\mathrm{w}} S_{\mathrm{S}}^{2} D_{\mathrm{r}}^{2}} \cdot \frac{e^{3}}{(1+e)}$

where $k_{\text {sat }}$ is the saturated hydraulic conductivity $\left(\mathrm{cm} \mathrm{s}^{-1}\right), g$ is the gravitational constant $\left(9.81 \mathrm{~m} \mathrm{~s}^{-2}\right), \mu_{\mathrm{w}}$ is the dynamic viscosity of water $\left(\approx 10^{-3} \mathrm{~Pa}\right.$ s at $\left.20^{\circ} \mathrm{C}\right), \rho_{\mathrm{w}}$ is the density of water $(998 \mathrm{~kg}$ $\mathrm{m}^{-3}$ at $\left.20^{\circ} \mathrm{C}\right), e$ is the void ratio $(-), S_{\mathrm{S}}$ is the specific surface $\left(\mathrm{m}^{2}\right.$ $\mathrm{kg}^{-1}$ of solids) given by the Chapuis and Légaré (1992) equation, $D_{\mathrm{r}}$ is the relative density of the solid grains (-) and $C$ is a factor that takes into account the shape and tortuosity of pore channels $\left(\approx 20\right.$ for $k_{\text {sat }}$ expressed in $\left.\mathrm{cm} \mathrm{s}^{-1}\right)$.

$\mathrm{KCM}: k_{\mathrm{sat}}=C_{\mathrm{G}} \frac{\gamma_{\mathrm{w}} \cdot e^{3+x}}{\mu_{\mathrm{w}}(1+e)} C_{\mathrm{U}}^{1 / 3} d_{10}^{2}$

where $C_{\mathrm{G}}\left(=0.1\right.$, for $k_{\mathrm{sat}}$, in $\left.\mathrm{cm} \mathrm{s}^{-1}\right)$,) and $x(=2)$ are two constants for granular materials; $C_{\mathrm{U}}\left(=d_{60} / d_{10}\right)$ is the uniformity coefficient (-) and $d_{10}$ and $d_{60}$ are the diameters $(\mathrm{cm})$ corresponding to $10 \%$ and $60 \%$ passing on the cumulative grain-size distribution curve.

The online version of the original article can be found at https://doi.org/ $10.1007 / \mathrm{s} 10040-020-02129-7$

Thomas Pabst

t.pabst@polymtl.ca

1 Department of Civil, Geological and Mining Engineering, 2500,

chemin de Polytechnique, Polytechnique Montreal,

Montréal, QC H3T 1J4, Canada

2 Research Institute on Mines and Environment (RIME),

Montreal, QC, Canada

3 Golder Associates Ltd, Montreal, Canada 